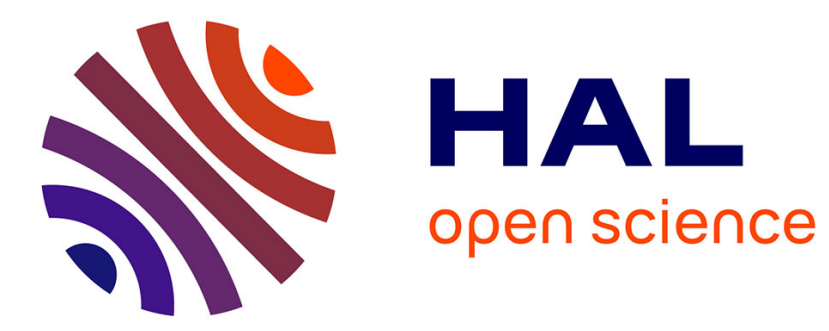

\title{
Spectroscopic investigation of refractory molecules produced by laser vaporization
}

J. Chevaleyre, C. Bordas, A. Valente, V. Boutou, M. Lebeault-Dorget

\section{To cite this version:}

J. Chevaleyre, C. Bordas, A. Valente, V. Boutou, M. Lebeault-Dorget. Spectroscopic investigation of refractory molecules produced by laser vaporization. Journal de Physique IV Proceedings, 1994, 04 (C4), pp.C4-687-C4-690. 10.1051/jp4:19944181 . jpa-00252641

\section{HAL Id: jpa-00252641 https://hal.science/jpa-00252641}

Submitted on 1 Jan 1994

HAL is a multi-disciplinary open access archive for the deposit and dissemination of scientific research documents, whether they are published or not. The documents may come from teaching and research institutions in France or abroad, or from public or private research centers.
L'archive ouverte pluridisciplinaire HAL, est destinée au dépôt et à la diffusion de documents scientifiques de niveau recherche, publiés ou non, émanant des établissements d'enseignement et de recherche français ou étrangers, des laboratoires publics ou privés. 


\title{
Spectroscopic investigation of refractory molecules produced by laser vaporization
}

\author{
J. CHEVALEYRE, C. BORDAS, A.M. VALENTE, V. BOUTOU and M.A. LEBEAULT-DORGET
}

Laboratoire de Spectrométrie Ionique et Moléculaire, URA 171 du CNRS, Université Lyon I, Bât. 205, 43 boulevard du 11 Novembre 1918, 69622 Villeurbanne cedex, France

\begin{abstract}
In classical ovens, vapour pressure of small molecules including refractory compounds is generally too weak to undertake their spectroscopic characterization in the gas phase. Laser sources as they allow any material to be vaporized whatever its melting point, bring a satisfactory answer to this problem.

We designed a source of this type with the aim to undertake the spectroscopic characterization of small molecules including carbon or nitrogen together with a metal of large astrophysical abundance ( $\mathrm{Al}, \mathrm{Mg}, \mathrm{Na}, \mathrm{Fe}$ ).

The first mass spectra of neutral molecules as well as ions produced by this source are presented in this paper.
\end{abstract}

\section{INTRODUCTION}

The observation of any molecule in astrophysical media relies on their preliminary characterization in the laboratory. For this reason, spectroscopic analysis of more and more complicated molecules, in connection with astronomers' observations, continues to be very fruitful for molecules containing the more abundant elements such as $\mathrm{H}, \mathrm{C}, \mathrm{O}, \mathrm{N}$ and $\mathrm{S}$. The situation is less favourable for metal-bearing molecules where observations in astrophysics as well as in the laboratory are less developped. They are mainly limited to molecules where metal atoms are associated with $\mathrm{O}, \mathrm{H}, \mathrm{S}$ and, except some noticeable exemples like $\mathrm{MgCN}^{1}$, very less is known about molecules including metal and $\mathrm{N}$ or $\mathrm{C}$ atoms. Obviously, this situation is due to the refractory character of those molecules that makes difficult the yield of large amounts in the gas phase.

In his wide review on the observations and chemistry of refractory elements in the interstellar medium, Turner ${ }^{2}$ came to the conclusion that a large laboratory effort is awaited to characterize carbides but especially nitrides of Al, $\mathrm{Na}$ or Mg that could appear preferentially than the corresponding oxides in some star-forming regions of the interstellar medium. Moreover, after the observation of $\mathrm{SiC}$ in IRC $+10216^{3}$, mono or polycarbides of $\mathrm{Al}, \mathrm{Mg}$ or $\mathrm{Fe}$ are expected to be observed too.

We present in this paper a laser vaporization source, especially designed to produce small molecules of refractory materials. Our preliminary results demonstrate the capability of this source to produce neutral molecules (AIC and $\mathrm{Al}_{\mathrm{n}} \mathrm{C}$ ), as well as ions directly ejected from the laser vaporization plasma ( $\mathrm{Fe}_{\mathrm{n}}{ }^{+}$ and $\mathrm{C}_{\mathrm{n}}{ }^{+}$). We shall give an idea of the investigations that will be conducted in 
forthcoming experiments with this source.

\section{EXPERIMENT}

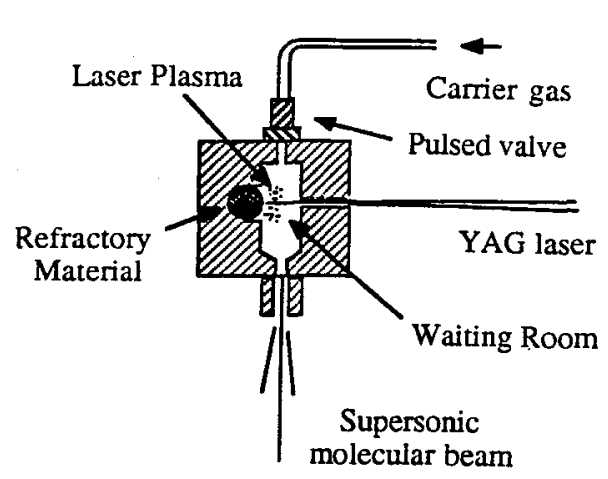

Fig. 1. The vaporization source.

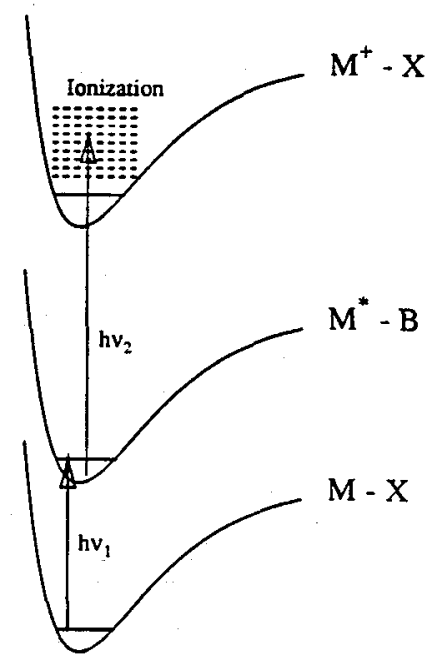

Fig. 2. Two photon ionization.
In a pioneering work by Smalley, the efficiency of laser vaporization sources to produce large amounts of refractory compounds in the gas phase has been demonstrated for any metal, up to the most refractory like molybdenum and tungsten 4 .

Briefly, a target rod is located in the throat of a pulsed nozzle (Fig.1). It is shot by the second harmonic of a pulsed YAG laser leading to metal vaporization and formation of a high temperature plasma. Before laser pulse, helium was injected into this source through a pulsed valve in such a way that the laser shot coincide with the maximum pressure of the helium carrier gas; the injection pressure can be varied in the 1-10 bar range. In the waiting room $\left(0.2 \mathrm{~cm}^{3}\right)$ begins the expansion of the laser plasma into the carrier gas with recombination and thermalization of the plasma and production of small molecules and clusters.

After the nozzle, these molecules and clusters continue to expand into the vacuum $\left(10^{-3}\right.$ torr), forming a cool molecular beam. A skimmer placed 1-2 cm downstream allows this supersonic molecular beam to enter the low pressure region $\left(10^{-6}\right.$ torr) where various excitation processes will be undertaken with different lasers. In any case, laser excitation results in the yield of ions. These ions are produced into the extraction region of a time of flight mass spectrometer (TOF), that permits mass characterization.

The simplest excitation is the direct ionization by one UV photon. Increasing the energy of this photon, new peaks of given masses appear as the photon energy 
reaches the ionization potential. By this way, ionization potentials can be easily determined. Moreover, photoionization efficiency as well as its evolution near the threshold can also be studied. In another scheme depicted in Fig.2, one photon excites the molecule to an electronically excited state while a second photon brings it beyond the ionization limit. By scanning the exciting photon over a given electronic state an ion signal is produced only when the exciting energy matches a $\mathrm{v}, \mathrm{J}$ level of this state, allowing its spectroscopic investigation.

\section{PRELIMINARY RESULTS}

We started the experimental program, with an aluminum rod, by the mass characterization of molecular species existing in the molecular beam. This was achieved by direct ionization with one UV photon provided by a frequency doubled excimer pumped dye laser. A typical spectrum is shown in Fig 3 with a photon energy: $5.6 \mathrm{ev}$. This spectrum exhibits a large series of $\mathrm{Al}_{\mathrm{n}}$ clusters, up to $n=40$, as they are usually produced in this kind of source 5 .

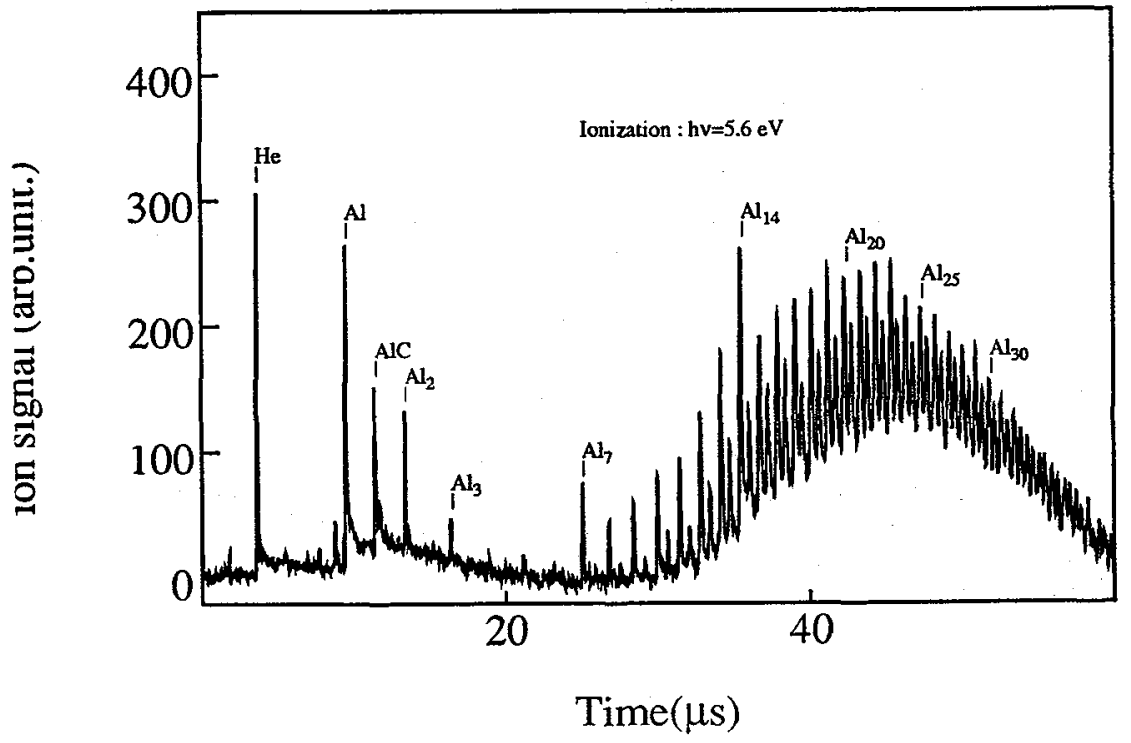

Fig. 3. Mass spectrum obtained by laser vaporization of an aluminum rod combined with direct one photon ionization.

As discussed in a former paper 6 , the most exciting feature of this spectrum is the appearance of mass peaks for the $\mathrm{Al}_{\mathrm{n}} \mathrm{C}$ molecules. The large intensity of the AlC mass peak gives us the opportunity to start with spectroscopic investigation of this molecule using the one photon resonant-two photon ionization 
technique and scanning the resonant photon over AlC electronically excited states. Moreover, we intend to undertake a systematic study of the ionization potential and photoionization efficiency of $\mathrm{Al}_{n} \mathrm{C}$ molecules. We expect valuable information regarding the $\mathrm{C}$-bonding with metal particles to be deduced from these experiments.

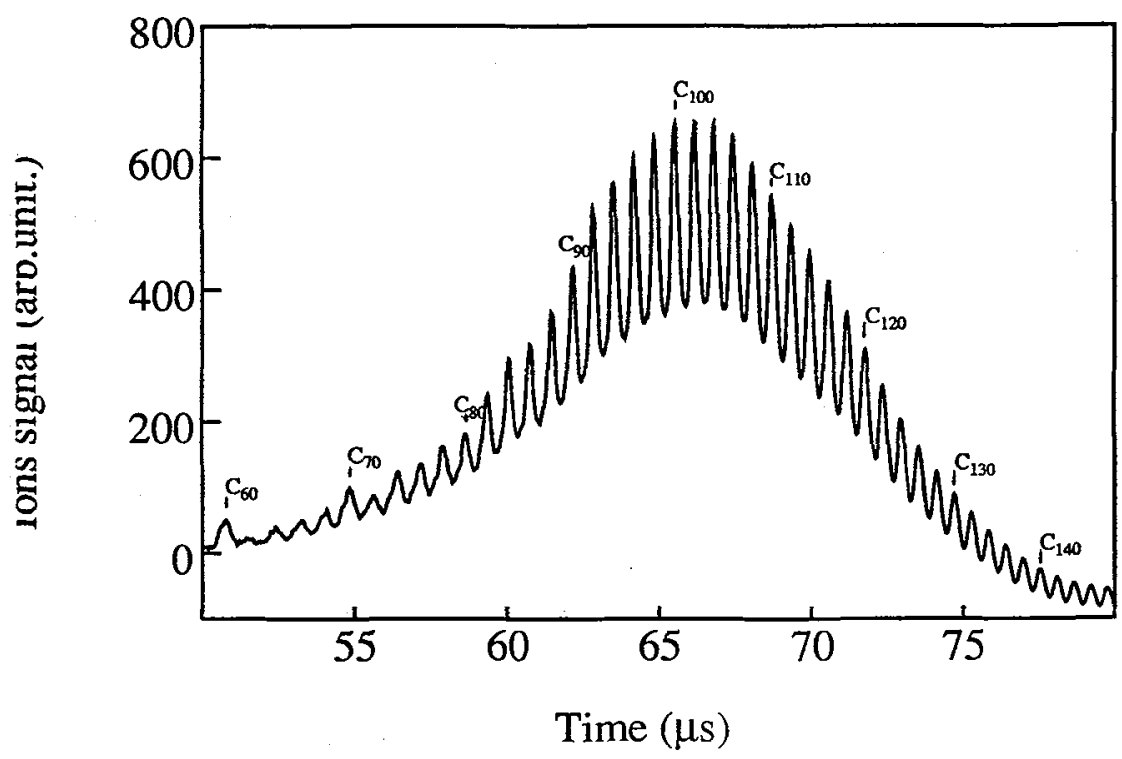

Fig. 4. Mass spectrum obtained by laser vaporization of a graphite rod.

In another way, by replacing the ionization laser by a high voltage pulse, we show up (Fig 4), by making use of a graphite rod, that large amounts of carbon ions, produced in the laser vaporization plasma, live all along the molecular beam. As a consequence, their spectroscopic characterization, by laser induced fluorescence, will be possible just downstream the nozzle.

\section{REFERENCES}

1. L. M. Ziurys, Physical chemistry of molecules and grains in space, Mont Ste Odile, France, september 1993

2. B. E. Turner, Astrophys. J. 376, 573 (1991)

3. J. Cernicharo, C. A. Gottlieb, M. Guelin, P. Thaddeus and J. M. Vrtilek, Astrophys. J.,341, L25 (1989)

4. J. B. Hopkins, P. R. R. Langridge-Smith, M. P. Morse and R. E. Smalley J. Chem. Phys., 78, 1627 (1983)

5. M. Pellarin, B. Baguenard, M. Broyer, J. Lermé and J. L. Vialle, J. Chem. Phys., 98, 944 (1993)

6. J. Chevaleyre, C. Bordas, A.M. Valente, V. Boutou, J. Maurelli, B.Erba and J. d'Incan, to be published 